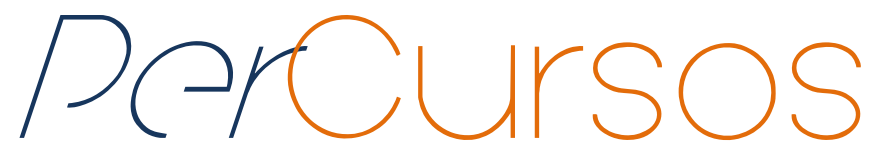

\title{
Novos parâmetros da ação coletiva numa localidade do bairro Monte Cristo - Florianópolis (2005 - 2010)
}

\begin{abstract}
Resumo
O objetivo do artigo é analisar os novos parâmetros da ação coletiva em uma localidade da periferia urbana de Florianópolis - SC. As mudanças nesta localidade são perceptíveis na comparação entre as práticas associativas e as relações de sociabilidade desenvolvidas nos primórdios da localidade e as desenvolvidas no tempo presente. Surgida do movimento dos sem-teto, os primeiros anos de existência da localidade foram marcados por intensas mobilizações coletivas e por relações de sociabilidade que valorizavam os espaços públicos da localidade e do bairro. Tendo como cenário o posterior esvaziamento dos espaços de organização coletiva e de sociabilidade, e partindo de dados coletados em pesquisa cuja metodologia baseou-se em entrevistas e na observação participante, são investigadas as instituições que fazem a mediação entre o plano local e o público. Com isto o artigo procura elucidar os novos parâmetros da ação coletiva nesta localidade do bairro Monte Cristo.
\end{abstract}

Palavras-chave: Ação coletiva. Periferia urbana. Florianópolis.

\section{Francisco Canella}

Doutorado em Ciências Sociais pela Universidade Federal do Rio de Janeiro - UFRJ. Professor na Universidade do Estado de Santa Catarina - UDESC franciscocanella@hotmail.com

\section{Para citar este artigo:}

CANELLA, Francisco. Novos parâmetros da ação coletiva numa localidade do bairro Monte Cristo - Florianópolis (2005-2010). Revista PerCursos, Florianópolis, v. 14, n.27. jul./dez. , 2013. p. $242-270$.

DOI: $10.5965 / 1984724614272013242$

http: //dx.doi.org/10.5965/1984724614272013242

\footnotetext{
${ }^{1} \mathrm{O}$ presente artigo é uma versão modificada do capítulo 4 da tese de doutorado de minha autoria, "Entre o local e a cidade: memórias e experiências de duas gerações de moradores da periferia urbana em Florianópolis (2011)".
} 


\title{
New paraments of collective action in a community of Monte Cristo neighborhood - Florianópolis (2005-2010)
}

\begin{abstract}
The goal of this paper is to analyze the new parameters of collective action in a periphery community of Florianopolis - SC. The changes observed in this locality are noticeable when comparing the associated practices and relations of sociability developed in the early days of the community town and the ones developed at the present time. Arising from the movement of the homeless, the early years of the town were marked by intense collective mobilizations and relations of sociability that valued the public spaces of the community and neighborhood. Against the backdrop of the subsequent emptying spaces of collective organization and sociability, and based on data collected in a research whose methodology was based on interviews and participant observation, institutions that mediate between local and public planes are investigated. Thereby, this article seeks to elucidate the new parameters of collective action in this locality of Monte Cristo neighborhood.
\end{abstract}

Keywords: Collective action. Urban periphery. Florianópolis. 


\section{Introdução}

A localidade do bairro Monte Cristo, em Florianópolis, SC surgiu do movimentos dos sem-teto. A ocupação que organizaram foi considerada, na perspectiva dos atores que a protagonizaram e/ou a apoiaram, bem sucedida, como tendo logrado êxito. Uma das razões deste êxito, e já muito destacado por aqueles que a analisaram, foi o fato de contarem com uma forte e coesa organização interna, que garantiu mobilizações eficazes, e um processo de negociação com o poder estatal em patamar de relativa igualdade. Tal coesão se fazia possível por meio de um discurso mobilizador que evocava a união coletiva e o sentimento de pertencimento à comunidade entre os moradores. Organizados pelo CAPROM (Centro de Apoio e Promoção ao Migrante), instituição criada por religiosos da Igreja Católica, o movimento dos sem-teto trazia toda a experiência e ideologia das comunidades eclesiais de base e pastorais. Os primeiros anos de existência da localidade foram, em razão destas práticas organizativas, marcados não só pelo forte componente político, mas também por intensas relações de sociabilidade ${ }^{2}$ Nessa localidade, a vivência e a celebração de espaços comuns eram parte do cotidiano dos moradores. Ainda hoje é comum ouvir dos moradores mais antigos, que participaram do movimento de ocupação, relatos sobre a solidariedade que havia nas relações entre os moradores neste momento da história da localidade. Esse saudosismo pode ser interpretado como uma captura do presente segundo Sarlo (2007, p. 9): o passado é rememorado como forma de falar sobre o presente. E este, após os anos iniciais de intensas mobilizações e agitada vida coletiva, passava a ser vivenciado como lugar do medo, do perigo, da violência, do "cada um por si", da "falação".

O que interessa para o presente artigo é que houve na localidade, em finais dos anos 1990, um significativo esvaziamento dos espaços de organização coletiva. A associação de moradores, que surgiu em substituição às originais comissões de moradores, consideradas mais democráticas e participativas do que o formato

\footnotetext{
${ }^{2} O$ conceito de sociabilidade é aqui incorporado no sentido de Simmel (2006, p. 66), para quem a sociabilidade não possui em si mesma nenhuma finalidade objetiva. Como coloca Zaluar (2009, p. 176) é "a interação em que não há motivos, fins ou interesses a não ser a própria interação, ou seja, a interação pela interação".
} 
centralizado e burocrático das associações de moradores, não fazia mais convergir todas as insatisfações e os ímpetos por mudança, presentes entre os moradores dos anos anteriores. O mesmo ocorria com os espaços de convivência comunitária: não aconteciam mais festas na comunidade, as ruas foram gradativamente se esvaziando, cedendo lugar ao medo coletivo e às reclamações entre vizinhos: "muita falação", "muito olho grande", "muita fofoca", "cada um por si" - tais eram as expressões mais ouvidas quando se pedia um depoimento sobre como estava a vida da comunidade.

A autoimagem negativa expressa nos relatos de muitos moradores da localidade, a constante referência à violência, as narrativas pautadas pelo medo e perigo, as reclamações quanto ao individualismo e à indiferença dos vizinhos revelavam igualmente um processo de enfraquecimento dos laços locais. Isso coloca a necessidade de analisar, no plano local, todo o processo que envolve a mudança naquele sentimento de pertencimento que se expressava, de modo mais evidente, na noção de comunidade. Talvez esse sentimento só tenha sido possível como uma "construção de lugar" de um movimento social que precisava de uma referência para se constituir como sujeito, e viabilizar as relações entre seus membros em uma conjuntura muito específica. No entanto, no decorrer dos anos fizeram-se valer as hierarquias e divisões existentes na cidade, pelas quais seus membros são inseridos (ou não) em suas relações, com suas consequências no plano local. Entre estas consequências pode-se citar o abandono das referências locais por parte dos moradores, especialmente quando se trata das novas gerações ${ }^{3}$.

Interessa aqui investigar em que medida a fragilidade do plano local está diretamente relacionada à presença limitada do Estado nesses espaços da cidade (ou até

\footnotetext{
${ }^{3}$ A mobilidade, tal como em Foote Whyte (2005), parece pressupor o abandono do local. É esse o movimento indicado pela geração dos jovens da localidade no caso aqui investigado. Se confirmada essa tendência, isto pode apontar, por um lado, para a existência de um padrão segundo o qual o crescimento da cidade conduziria ao predomínio de relações de sociabilidade marcadas pela impessoalidade, tal como nas análises de Simmel (1979) sobre a metrópole, e pela atitude blasé. Por outro lado, seria um indicador da redução de importância âmbito local na vida das cidades, seja por se estar tornando inviável para seus moradores, seja por ocupar cada vez menos espaço na sociabilidade das pessoas. A este respeito, Bauman (2003) destaca a fragilidade do local em tempos de globalização. Parafraseando-o, a questão remete a pensar o "local do frágil" na sociedade atual. Caberia, assim, indagar sobre qual o lugar do frágil na cidade: o que Florianópolis faz, afinal, com suas áreas pobres?
} 
mesmo ao seu abandono). Para tanto faz-se necessário avaliar seu grau de penetração, analisando a relação estabelecida pelos moradores com os agentes estatais. Para além de uma análise institucional, que investiga de modo sistemático, criterioso e exaustivo o uso e as percepções dos moradores dos espaços institucionais, a intenção aqui é incorporar à análise o tipo de relação que seus moradores estabelecem com as instituições e seus agentes, o que significa elucidar como os moradores desta localidade do bairro Monte Cristo se relacionam, em suas práticas cotidianas, com a cidade e outros espaços extralocais. Essa relação não é estática nem uniforme pois, como nos ensina Löic Wacquant, depende dos atores sociais, cuja ação, autônoma e imprevisível, coloca sempre a possibilidade de criação de novos laços e novas compreensões críticas (WACQUANT, 2005, p. 11). Por isso é necessário um olhar direcionado à ação no plano local, confrontando análises que produzem a invisibilidade da ação dos atores por focálos apenas na ordem pública da esfera citadina. Sobre isso, Alba Zaluar (2009) observa que o diagnóstico pessimista de muitos autores decorre exatamente da análise apenas na esfera metropolitana, marcada pelo encontro entre estranhos e diferentes, mais formal e impessoal, além de estar sujeita ao maior controle do Estado. Sugere então a incorporação da tipologia de Albert Hunter, que distingue três ordens sociais: a privada, a paroquial e a pública. Na análise deste autor, a vida pública e as instituições políticas enfraqueceram-se, reduzidas a uma relação de troca de impostos por serviços públicos, mas considera a importância da existência de uma ordem intermediária entre a ordem privada e a ordem pública. Observa que é nessa ordem intermediária, a paroquial, que residiria a dificuldade de controle social por parte do Estado (HUNTER, 1985, p. 238-239). É com base nessa interpretação que Zaluar questiona:

\footnotetext{
"É nessa esfera intermediária que devemos procurar as medidas do controle social que o Estado não pode nem deve exercer, por ser meramente coercitivo, impessoal, formal. Como esta ordem paroquial (ou vicinal) se transformou, se organizou e se manteve até hoje? Como e onde podem as localidades interferir nas políticas públicas para diminuir os riscos de viver em metrópoles, globais ou não, mas todas altamente diferenciadas e conflitivas?" (ZALUAR e RIBEIRO, 2009, p. 177)
}

No modo como se configura a realidade aqui investigada, a escola, o posto de saúde e as associações de moradores são algumas das instituições que fazem a mediação 
entre o plano local (o paroquial, na terminologia de Hunter) e o público ${ }^{4}$. É partindo dessa compreensão que são analisadas questões como o modo como se estabelecem as mediações entre o plano local e a esfera citadina, e sob quais parâmetros se desenvolvem as ações coletivas no âmbito local. Assim, após uma breve descrição da localidade e seus moradores, veremos como os moradores se articulam com as instituições que habitam esta esfera intermediária entre o privado e o público, e como os seus espaços associativos encaminham demandas na esfera pública.

\section{O bairro, a localidade e seus moradores}

Às margens da Via Expressa (que faz a principal ligação entre a BR 101 e as pontes de acesso à ilha de Santa (atarina), encravada numa área identificada como sendo uma das três principais concentrações de favelas de Florianópolis (o bairro Monte Cristo), situa-se a localidade aqui investigada. O Monte Cristo é mais adensado que outra área da cidade que concentra pobreza em Florianópolis, constituída pelas localidades adjacentes ao centro da cidade, conhecidas como "comunidades do Maciço do Morro da Cruz". 5

A área que as casas ocupam é de aproximadamente 0,811 hectares (8.110 metros quadrados). Está circunscrita a um perímetro de formato triangular, delimitada externamente por duas ruas e pelos muros de um conjunto residencial. Ao total, seis ruas formam a localidade. A sensação de quem chega é a de entrar: o espaço é bem circunscrito, a "comunidade" "fecha-se sobre si mesma". A partir de uma rua central, um pouco mais larga, e toda pavimentada com lajotas (como as demais), duas ruas mais estreitas, além de uma pequena travessa, cortam latitudinalmente a localidade. Os lotes

\footnotetext{
${ }^{4}$ De acordo com Albert Hunter, a ordem paroquial teria as seguintes bases: "The parochial social order is based on the local interpersonal networks and interlocking of local institutions that serve the diurnal and sustenance needs of residential community - the local stores, schools, churches, and voluntary associations of various kinds". (Hunter, 1985, 233). Tradução do autor: "A ordem social paroquial é baseada nas redes interpessoais locais e na interligação de instituições locais que atendem as necessidades diárias e de sustentação da comunidade residencial - o comércio local, escolas, igrejas e associações de voluntários de diversos tipos".

${ }^{5}$ Ao se escrever sobre áreas urbanas como o Monte Cristo tem sido empregado o termo periferia. Mais do que atender a um propósito de localização geográfica, o termo parece estar sendo empregado como eufemismo para designar o local onde vivem os pobres nas cidades. Guaciara Freitas (2009) em artigo recente discute como o termo "periferia" foi assimilado ao discurso da mídia brasileira para designar de forma genérica o lugar onde vivem os pobres.
} 
são amplos, o que permitiu a ampliação das casas (as casas, em seu projeto original, têm área construída de 40,6 metros quadrados). Por conta das ruas calçadas, cujo traçado seguiu um desenho urbano previamente planejado, sua aparência em nada se assemelha às tradicionais favelas, com suas ruas tortuosas e uma alta densidade de áreas construídas, cuja distribuição logo denuncia uma ocupação espontânea, marcada pelo improviso e pela precariedade.

Atualmente a localidade é habitada por 230 moradores/as, distribuídos em 58 domicílios. Das famílias fundadoras, remanescentes da ocupação, tem-se ainda vivendo lá 25 famílias - ou seja, metade das que estiveram no movimento de vinte anos atrás. Por conta desse passado comum marcado pelas lutas, há uma divisão entre as famílias fundadoras, que participaram da ocupação, e as famílias que vieram depois. No senso comum criado na localidade, aqueles que participaram da ocupação são os que mais atuam em espaços coletivos.

No início da década de 1990, eram aproximadamente 180 ocupantes. Destes, havia cerca de 97 crianças e adolescentes. Muitas jovens famílias, com crianças pequenas, algumas sem filhos ainda. Uma década depois, estavam com 253 moradores. O número manteve-se constante até 2005, quando o número de moradores estava em torno de 245 moradores. No entanto, em 2010 o número de moradores reduziu-se para 230 moradores. Mesmo não sendo uma redução significativa, é interessante observar que ela é acompanhada do aumento do número de domicílios, ocorrendo portanto uma redução da média de moradores por domicílio: em 1990, a média ficava em 3,7 moradores por domicílio. Em 2000 temos 5,0 moradores por domicílio; em 2005, 4,8 e, em 2010 a média volta a descer, com 3,9 por domicílio ${ }^{6}$.

A construção de mais casas significou uma melhoria nas condições de moradia (pois passaram a viver menos moradores por domicílio), e não se traduziu em maior adensamento populacional da área. Também é perceptível a melhoria em parte das casas. Algumas progrediram, muitas casas tornaram-se maiores, outras ficaram mais ajeitadas, com boas casas e embelezadas. No entanto, há a deterioração de muitas casas. Mas a

\footnotetext{
${ }^{6}$ É interessante comparar esses dados com os apresentados por realidades como a da favela carioca de Acari, que apresenta uma média de 800 habitantes por hectare (ALVITO, 2001): no caso aqui analisado a média é de 284 habitantes por hectare. O bairro do Monte Cristo como um todo, por sua vez, apresenta uma média de 215 habitantes por hectare.
} 
dinâmica de empobrecimento convive com uma melhoria nas condições de vida de uma parcela de seus moradores. Na mesma vizinhança é possível perceber as casas que ao longo dos anos vão ficando deterioradas. A tendência que parece predominar é a dos mais pobres acabarem vendendo e indo morar mais distante, nas periferias dos municípios vizinhos, cedendo lugar àqueles que chegam motivados a morar num bairro mais próximo do centro da cidade. A vinda de novos moradores está relacionada a esse processo.

A maioria da população tem 19 anos ou mais, o que não acontecia nos outros períodos. Houve uma diminuição bastante significativa do número de moradores com idades entre 12 e 18 anos, ou seja, do segmento que envolve os adolescentes, alvo preferencial da maior parte dos projetos socioeducativos. É comum entre as famílias do bairro o entendimento de que é nessa fase da vida que é feita a escolha entre ser trabalhador, seguir uma vida honesta, ou ingressar na marginalidade e virar bandido. Tal referência cronológica parece bastante consolidada entre eles. É o que nos diz um dos mais assíduos participantes dos projetos desenvolvidos pela universidade na localidade. Embora lamente o final das atividades, se conforma com o seu final, pois coincidiria com o final da juventude.

- Isso daí foi... foi se acabando. Um fazia uma coisinha aqui, outro fazia lá, e aí se acabou. Onde uns já tão sendo pai, outros já tão... Ainda bem que ninguém do grupo não caiu, assim, nas drogas, ou coisa pesada, assim... Tão tudo trabalhando. Das equipes de tutor tão trabalhando. Pra tu ver como o projeto teve importância... Pode ter acabado, mas acabou assim... na hora que era para acabar, ele acabou, entendeu?" (Renato, morador da localidade).

De todo modo, no comportamento da nova geração constata-se uma tendência à privatização das relações. O grupo aqui analisado, cessada a fase em que os grupos de amizade confundiram-se com os projetos socioeducativos, onde tinham intensa convivência coletiva, ingressaram na idade adulta, quando então foram rompidos ou enfraqueceram-se os laços de amizade e convivência. Somado ao fato de que nas novas famílias que chegaram alguns anos após a ocupação, essa característica do comportamento da nova geração tem seus efeitos mais evidentes no esvaziamento dos espaços coletivos de participação e convivência. Em contrapartida, constata-se a 
presença de práticas políticas clientelistas (algo impensável nos primeiros anos que se seguiram à ocupação). Igualmente verifica-se o crescimento de igrejas pentecostais, que desestimulam o desenvolvimento de sociabilidades coletivas nos espaços que não os da igreja. Tais novidades na localidade podem ser vistas como consequências que acompanharam o esvaziamento dos espaços onde se desenvolviam as antigas sociabilidades. A análise dos espaços coletivos no plano local e a prática dos moradores permite uma melhor compreensão dessa nova tendência na localidade.

\section{As instituiç̧̃̃es públicas: a escola}

A escola é uma das instituições que fazem a mediação entre o plano local (o paroquial, na terminologia de Hunter) e o público. Nela se concentram as expectativas educacionais dos moradores. A preferência das famílias quando se trata da educação infantil é encaminhar suas crianças a uma instituição filantrópica conveniada à prefeitura (instituição de caridade bastante presente e bem acolhida pelos moradores). Para o encaminhamento de seus filhos em idade escolar, a escolha da maioria das famílias recai sobre uma escola estadual, que oferece todas as séries escolares, da educação infantil até o ensino médio, incluindo curso noturno) e outra municipal, que oferece o ensino fundamental. Tem sido uma trajetória comum a eles iniciar a educação infantil nesta instituição filantrópica (que se localiza no Monte Cristo) e seguir para a escola municipal e realizar o ensino médio na escola estadual (ambas no vizinho bairro de Capoeiras). A localização próxima sem dúvida define a preferência por essas escolas. No entanto, poucas famílias fazem a escolha de colocar seus filhos na escola estadual do bairro Monte Cristo, que, embora no mesmo bairro, se localiza um pouco distante, em outra localidade. Mais do que a distância, pesa nessa escolha a rivalidade entre as “comunidades". É comum não frequentarem o espaço uma da outra. Pesa também uma ideia difundida de má qualidade da escola: é popularmente conhecida entre os moradores como o "vai quem quer". 
No entanto, em se tratando de educação dos filhos, cabe a observação acerca do crescente prestígio dos espaços educativos extraescolares e dos "projetos"7. Se pensarmos a função social da escola de intermediação entre a esfera pública mais ampliada da cidade e a esfera local, a escola parece perder terreno para projetos e iniciativas do Terceiro Setor. O desprestígio da instituição escolar fica explicitado na alcunha conferida a uma das escolas do bairro, o "vai quem quer". Em tal apelido jocoso, revela-se uma crítica à incapacidade da escola em cumprir uma função tão cobrada pelas famílias de classe popular, que é a imposição da disciplina e da obediência a seus filhos. Qualquer um entra, se quiser - se não quiser, não vai. Na percepção dos moradores a relação entre estudante e escola está centrada no desejo e na vontade do estudante, e não na autoridade da escola ${ }^{8}$.

Essa dificuldade na preservação de uma posição de autoridade da instituição escolar é acompanhada da convivência com muitas instituições para o tratamento da pobreza. Tal fenômeno é verificado em muitos outros bairros das periferias urbanas de várias cidades brasileiras. É interessante que essas instituições, no caso do Monte Cristo, têm origem entre atores sociais organicamente e historicamente ligados a eles. Tais instituições têm em comum a forte presença de pessoas da Igreja Católica ou muito próximas a ela. São antigos militantes de movimentos sociais, que atuavam a partir das comunidades eclesiais de base (CEBs) ou das pastorais, articulando-se com desenvoltura entre os moradores nas diversas localidades da periferias de Florianópolis. Com toda uma legitimidade conquistada nas lutas que marcaram o passado recente da cidade, hoje atuando em espaços formalizados, esses agentes têm tido papel fundamental na articulação de algumas das demandas da população dessas localidades (relativas à educação e formação profissional) com órgãos governamentais e instituições do Terceiro Setor. As atividades desenvolvidas por essas instituições envolvem boa parte do tempo

\footnotetext{
7 Nas duas últimas décadas foram tão difundidas estas experiências que alguns autores, como Regina Novaes (2006), têm empregado o termo "jovens de projeto".

${ }^{8}$ Embora exista essa crítica explícita a uma das escolas, as outras escolas públicas que atendem ao bairro também ficaram nas últimas colocações entre as escolas públicas de Florianópolis no IDEB (Índice de Desenvolvimento da Educação Básica) de 2010. O IDEB, criado pelo Ministério da Educação, mede a qualidade das redes pública e privada de ensino básico fundamental e médio, com base nas notas obtidas na Prova Brasil/Saeb e em informações sobre fluxo escolar encaminhadas pelos estados e municípios, por meio do censo escolar.
} 
livre das crianças e jovens da localidade, e são bastante aceitas e valorizadas por suas famílias. São estimulados à participação por suas famílias por conta da necessidade de mantê-los afastados das drogas e da criminalidade. Pais e mães da localidade não se cansam de repetir o bordão: “cabeça vazia, oficina do diabo". A outra demanda que os pais acreditam ser suprida nesses espaços é por trabalho: apostam em uma possibilidade de profissionalização de seus filhos a partir de cursos, oficinas e vagas em estágios oferecidas por meios desses novos espaços atuantes no bairro.

No entanto, percebe-se também o envolvimento das escolas com os principais atores do bairro. Em um dos casos constatei uma participação intensa nos assuntos comunitários. Isso acontecia de diferentes formas, seja cedendo o seu espaço para reuniões e eventos comunitários, seja com a participação direta de seus membros (professores e funcionários) em atividades de interesse do bairro. Durante a minha pesquisa de campo, presenciei ao menos três situações que atestam esse envolvimento.

A diretora de uma das escolas do bairro participou ativamente da organização do evento de Integração do Monte Cristo, organizado pelo Conselho de Associações da Região do Monte Cristo (CARMOCRIS). Os portões da escola foram abertos para o apoio a atividades (guardar o material, fazer a alimentação, uso dos banheiros) e por ela circulavam com desenvoltura e intimidade muitas das lideranças e mães de estudantes, tanto no dia da atividade como nos dias que antecederam o evento.

A mesma escola cedia seu espaço para reuniões comunitárias e para atividades como a organização das demandas comunitárias visando o Programa de Aceleração do Crescimento (PAC) ou para atividades de uma rádio comunitária desenvolvida por jovens militantes estudantis da UFSC. A convite de lideranças locais, acompanhei algumas dessas reuniões, e nelas foi possível perceber com clareza o quanto a diretora da escola, assim como alguns outros professores e funcionários da escola, desenvolvem um bom diálogo, resultado de um longo convívio em atividades envolvendo a escola e lideranças de diversas localidades do bairro, além de outros atores externos (caso dos jovens universitários que organizavam uma rádio comunitária).

A diretora de outra escola do bairro também aceitou integrar a direção da organização fundada por uma liderança local, o Conselho dos Moradores do bairro. Para 
fundar essa associação, um conjunto de lideranças insatisfeitas com o CARMOCRIS tentou articular um conselho alternativo. Para tanto, buscaram o apoio de diversas figuras que eram referência no bairro - entre elas a diretora da escola.

Em todas essa ocasiões pude perceber a proximidade existente entre esses diretores e as lideranças e moradores comuns do bairro, e a intimidade que tinham com seu problemas cotidianos, mesmo não sendo eles moradores do bairro. O contato direto e pessoal dos moradores, de suas lideranças com esses diretores, trazendo até a escola problemas locais, mesmo que não diretamente relacionados à educação de seus filhos, é bastante constante. Tal relação pode também ser evidenciada quando uma importante liderança reclamou das interferências político-partidárias nos "assuntos comunitários", ou mesmo do trabalho eleitoral feito pelos seus adversários políticos, as quais se efetivam valendo-se da influência de alguns membros da direção ou do corpo docente das escolas da região. Tal potencial de busca de votos está, evidentemente, relacionado a algum nível significativo de inserção entre os moradores.

Tal relação é mais evidente no caso da escola do bairro, da escola municipal de ensino fundamental situada em Capoeiras, e da instituição filantrópica. A escola estadual de Capoeiras, dada a sua localização, e principalmente a abrangência de seu público (envolvendo muitos estudantes, provenientes de diferentes bairros), já é tomada como um espaço institucional mais distante e impessoal ou, em outras palavras, mais pública (e menos paroquial, se tomarmos a terminologia de Hunter).

A escolarização da população da localidade também é elucidativa. Alguns dados anteriormente coletados em pesquisa sobre a relação entre as famílias e a escola revelaram que é impossível estabelecer qualquer relação entre supostos "modelos familiares" e o desempenho escolar. Na medida em que havia (e há) uma forte presença de famílias monoparentais com chefia feminina, foram estabelecidas em tal pesquisa comparações entre o desempenho escolar dessas famílias com os filhos das outras famílias (conjugais) e com a escola. Ao conduzir a análise dividindo as famílias entre as que apresentavam filhos com defasagem escolar e as que não apresentavam filhos com defasagem, o estudo revelava que não havia nenhuma diferença significativa. A baixa escolaridade na geração dos pais era generalizada. Se considerarmos que a baixa 
escolaridade dos pais se constitui em um fator explicativo do baixo rendimento escolar dos filhos, ela não pode ser considerada um fator exclusivo: a pesquisa revelava que outras famílias com o mesmo perfil de baixa escolaridade apresentavam filhos com bom desempenho escolar. O mesmo raciocínio valia no que se referia à renda: embora grande parte das famílias fosse de baixa renda, os resultados escolares não eram os mesmos. Finalmente, é importante observar ainda que a pesquisa constatava uma tendência que permanece, referindo-se a uma mudança recente no comportamento com relação à escola, que é a de maior longevidade escolar ${ }^{9}$. Essa tendência talvez explique a valorização dada pelas mães à instituição escolar: quando perguntadas sobre a importância da escola, foram unânimes em afirmar que valorizam a escola. No entanto, não possuem o repertório de práticas familiares que possam garantir uma mudança na vida escolar de seus filhos.

Já com relação aos filhos, a pesquisa constatava que para a maior parte dos entrevistados, a escola estava em segundo plano, vindo " a reboque" da vida ${ }^{10}$, tal como o foi para a geração anterior, cujos depoimentos, mais especificamente o das mães, eram marcados pela ausência de lembranças escolares mais significativas. Nesse contexto, a família acaba por não desempenhar um papel motivador, mesmo que reconheça a importância dos estudos: não existem cobranças quanto ao desempenho escolar dos filhos, e muito menos ajuda nas dificuldades escolares. Além disso, outras dificuldades se somam, tais como o espaço domiciliar precário, que não apresenta condições físicas para constituir-se em espaço de estudo.

Sintoma dessa fraca vinculação com a escola era o fato (constatado principalmente entre aqueles jovens com maiores defasagens escolares) de que seus círculos de amizade eram construídos na sua maior parte na própria localidade. Nos casos em que existiam vínculos fortes fora da comunidade, estes eram com parentes ou antigos vizinhos que se mudaram para outros bairros (Canella, Vidal e Pitta, 2004, p. 9). Escola e

\footnotetext{
${ }^{9}$ A pesquisa constatava que entre os que à época tinham acima de 19 anos, apenas $14,3 \%$ tinha concluído o ensino fundamental, enquanto a nova geração ( jovens que então se encontravam com idades entre 15 e 17 anos) $28 \%$ (ou seja; o dobro) havia concluído ou estava concluindo o ensino fundamental sem defasagens escolares.

${ }^{10}$ Expressão utilizada por Nadir Zago (2001).
} 
vizinhança são mundos sociais que pouco se comunicam, no caso desses jovens com problemas de mau desempenho em suas trajetórias de vida escolares.

\section{As instituições públicas: o posto de saúde}

O posto de saúde localiza-se muito próximo da localidade aqui analisada. Numa população onde a grande maioria não tem recursos para atendimento médico particular e/ou planos de saúde privados, o posto de saúde municipal torna-se uma instituição de visibilidade no bairro, referência importante da vida coletiva de várias localidades. Mais do que isso, também se converte em espaço de participação. Várias associações de moradores se fazem representar no Conselho de Saúde local, o que é revelador da sua importância, pois promove articulações comunitárias num contexto de esvaziamento de espaços de participação coletiva. A urgência das questões de saúde em um contexto de precariedade do atendimento explica porque a questão de saúde constitui-se em fator de mobilização coletiva, diferentemente do espaço escolar, limitado em seu alcance, pois é restrito àquelas famílias que possuem filhos frequentando a escola. As questões de saúde, ao contrário, atingem a todos. Além disso, a dificuldade de comunicação entre pais e escola, para a qual os pais têm dificuldade em encaminhar suas demandas, em razão da pouca compreensão de seus mecanismos de funcionamento, e do descompasso entre suas expectativas e os objetivos da instituição escolar, não se apresenta no caso da saúde. Todos têm muito claro qual é a sua demanda, o que é bom atendimento ou, na verdade, o próprio atendimento. Dificuldades em marcação de consultas, falta de médicos e de infraestrutura acabam por mobilizar os moradores, que muitas vezes encontram nos próprios agentes oficiais seus aliados: médicos, enfermeiros, atendentes compõem as comissões locais de saúde e articulam suas reivindicações por melhores condições de trabalho. Acompanhando algumas reuniões da comissão, pude observar as dificuldades que sofrem com um atendimento precário e discriminatório por parte do poder público.

Foi possível no contexto de uma investigação realizada no bairro acompanhar algumas dessas mobilizações. A maior delas envolveu a luta pela melhoria do atendimento de um hospital público, o Hospital Florianópolis. Culminou com uma 
passeata pelas ruas centrais do bairro Estreito (região continental de Florianópolis), finalizando no hospital. Ao longo do trajeto, percorrido de forma ordeira e pacífica, e com o acompanhamento da Polícia Militar, foram distribuídos panfletos em folha tamanho A4 contendo o "Manifesto das Comunidades Atendidas Pelo Hospital Florianópolis", no qual os direitos à saúde da população (onde se evocava a Lei Orgânica da Assistência Social), a situação de precariedade do hospital, e as reivindicações do movimento eram explicitadas.

No entanto, em que pese a questão da saúde mobilizar mais as lideranças comunitárias, isso não chega a propiciar a superação da situação de isolamento que a maioria das lideranças enfrenta cotidianamente em suas localidades. No entanto, isso não significa uma apatia da população frente a essas instituições. Escola e posto de saúde não raramente tornam-se foco dos conflitos locais: são comuns os relatos de agressões sofridas por funcionários dessas instituições, o que pode ser entendido como reação ao descaso e o pouco investimento do poder público no atendimento da população das áreas mais pobres da cidade. E, o que é importante, tais reações, mesmo que traduzidas em comportamentos agressivos espontâneos, revelam a existência de expectativas da população com relação a essas instituições, e de questões que as lideranças enfrentam cotidianamente em suas localidades. A passeata ilustrava esse descompasso entre lideranças, as demandas, e a participação dos moradores: mesmo mostrando força ao congregar representantes de várias localidades atendidas pelo Hospital Florianópolis, ali se encontravam participando da mobilização quase que exclusivamente os presidentes e membros mais ativos das respectivas localidades.

\section{Os espaços associativos: as associações de moradores}

As associações encontram-se bastante reduzidas em seu papel agregador. $\mathrm{Na}$ maioria dos casos, são poucos a assumir a tarefa de organização dos moradores. Aqueles que se dispõem a assumir o encargo de dirigir uma associação de moradores encontram dificuldades até em montar uma chapa. Muitas vezes o fazem na base do compadrio, da relação de amizade, de algum favor devido. Como exemplo, é possível citar o caso de uma liderança que ajudou a retelhar uma casa. O retorno, a gratidão do vizinho que teve a 
casa retelhada, foi compor a nominata para a eleição para a associação de moradores. Após a composição da nominata, apenas um pequeno grupo e, não raro, uma única pessoa (normalmente o presidente) encarrega-se do trabalho da associação. No caso aqui analisado é isso que tem acontecido. Mas tais associações e suas lideranças, em muitos casos verdadeiros "exércitos de um homem só", vocalizam as reivindicações, ou melhor, traduzem muito daquilo que "sua base" sente e deseja (mas pelo qual não se mobiliza) em reivindicação.

Em vários bairros populares verifica-se este tipo de esvaziamento. A tendência reclamada por muitos de uma privatização das relações (o “cada um por si”) pode ser imputada aos "laços fracos”, típicos da territorialização de uma nova pobreza (Wacquant, 2005, p. 195-6), podendo mesmo ser interpretada como constituindo um novo padrão de sociabilidade instaurando-se na área, e que pode ser atribuída à presença cada vez mais constante de moradores sem qualquer vinculação com algum passado de lutas coletivas. Mas é também escolha de muitos que participaram dos movimentos de ocupação de terras: das 25 famílias remanescentes do período da ocupação, somente seis estão com algum de seus membros participando em espaços coletivos. A maioria tem preferido iniciativas individuais para solucionar os seus problemas. Na verdade, já há algum tempo essa tendência tem prevalecido, como na questão da cobrança de IPTU, que há cerca de uma década afetou a maioria dos moradores. Na ocasião, não recorreram à associação de moradores, optando por soluções individualizadas, em muitos casos por meio do acionamento das tradicionais redes clientelistas, envolvendo políticos e agentes estatais. Os problemas individuais cada vez menos são traduzidos na forma de uma demanda coletiva (tal como faziam na época do movimento dos sem-teto). Quando buscam algum apoio, este é buscado ou na sua rede privada de relacionamentos, ou em algum órgão público, contando então com a ajuda de alguém que se vale de sua posição para estabelecer então uma troca de favores, na melhor tradição clientelista.

Ao mesmo tempo, as associações perderam espaço para organizações nãogovernamentais (ONGs). Nas reuniões da CARMOCRIS, foi bastante comum ouvir reclamações quanto a isso. Em reação a este processo, as organizações dos moradores vêm realizando esforços na busca de questões que se convertam em demandas 
articuladoras da coletividade para poderem se manter atuantes. Dentre elas, têm priorizado a luta por espaços de lazer. Em torno dessa questão, procuram articular outras reivindicações, tais como a distribuição de recursos na cidade e projetos visando a ocupação do tempo livre da juventude.

\section{A luta pelo Parque Metropolitano}

Um exemplo de um processo que envolveu as lideranças locais e das comunidades vizinhas foi a luta pelo Parque Metropolitano. Mobilizou lideranças locais em um longo processo de negociações que, no final, conseguiu reverter a venda de um terreno da COHAB. Metade de um imenso terreno localizado nas proximidades do maior supermercado da área e às margens da Via Expressa seria então destinado à instalação de um parque. Tal ideia, no entanto, nem sempre foi bem recebida pelos moradores, que viam a proposta com desconfiança. Por um lado, porque poderia ficar restrito apenas ao uso de moradores de uma área específica; por outro, porque caso fosse relegada pelo poder público (como é comum acontecer com equipamentos urbanos nessa área), poderia se converter em mais um território de traficantes.

O movimento em defesa do parque desencadeou-se quando os moradores viram uma placa anunciando a venda do terreno em uma de suas margens. Como tinham conhecimento da existência de um projeto de autoria do urbanista Lino Peres criando um parque na região, as lideranças resolveram se mobilizar, e solicitaram uma audiência com a presidência da COHAB. A reunião evidenciou que havia um interesse da companhia na venda. Diante da reação dos moradores, a estratégia empregada pela presidência foi, por um lado, a de apresentar a situação como irreversível diante das decisões já tomadas (as quais eram atribuídas a processos cujo desenrolar era anterior à gestão atual da companhia e sobre os quais não tinham mais qualquer controle e responsabilidade) ${ }^{11}$. Por outro lado, a companhia procurou manter as lideranças afastadas dos detalhes do processo, alegando sigilo judicial imposto à transação de venda do terreno.

\footnotetext{
${ }^{11}$ A venda do terreno acontecia por determinação judicial, como parte de uma ação movida contra a Companhia por dívidas.
} 
As lideranças propuseram então a realização de uma audiência pública. Após um longo processo de negociação (e com a desistência do comprador), a COHAB concordou em ceder metade da área do terreno para a construção do parque, que deveria ser implementado e executado por meio de recursos da Prefeitura. Além da pressão organizada das lideranças do bairro, contribuiu para o êxito das negociações a proximidade política entre o secretário estadual de Desenvolvimento da Região da Grande Florianópolis (designado pelo governador para fazer a mediação do conflito entre os moradores e a $(\mathrm{OH} A B)$ e o prefeito de Florianópolis. Houve o interesse mútuo em não se desgastarem em ano eleitoral contra uma reivindicação de apelo popular. Durante as negociações as lideranças valeram-se do conhecimento da legislação, evocando o fato de aquela área ser classificada como Área de Interesse Comunitário (AIC), o que não permite a construção de estabelecimentos com finalidade comercial.

O acompanhamento desse processo de mobilização e negociação possibilita a reflexão em torno de alguns aspectos relativos aos espaços associativos no bairro Monte Cristo. Um deles refere-se à capacidade de mobilização. Ao contrário do que uma primeira aproximação possa sugerir, as lideranças não são tão frágeis como aparentam ser. No episódio em questão é importante destacar que souberam com quem se assessorar, empregaram boas estratégias para pressionar nas negociações, e demonstraram capacidade de mobilizar suas bases. No dia do ato de lançamento do parque, os moradores compareceram ao evento, no qual políticos locais (prefeito, secretários estaduais, vereadores) se fizeram presentes. Uma antiga liderança da época das ocupações dos sem-teto, quando das primeiras tentativas de negociação, falava, em tom ameaçador "ah! Eles não sabem com quem estão se metendo". Repetidas vezes disse: “eles vão ver o que vai acontecer [se o terreno for vendido]..." enquanto aguardávamos nas salas de espera de reuniões com a direção da COHAB. Mais que um simples saudosismo, esse tom de ameaça revelava uma aposta na capacidade de ainda mobilizarem o conjunto de moradores em ações coletivas, com impacto na mídia, e podendo perturbar as autoridades com suas denúncias. Sua avaliação era que havendo problema, os moradores comuns, aqueles que não são lideranças, viriam e participariam. E agora havia um problema. E nisso reside uma segunda questão a ser discutida. 
A certeza daquela liderança em sua ameaça, que primeiro pode ser interpretada como uma possível ilusão, motivada por um saudosismo da época em que o movimento dos sem-teto era fortemente organizado, na verdade se assentava na centralidade que a questão dos espaços de lazer adquiria no idioma de ação dos moradores. Toda uma discussão sobre violência e criminalidade, presença das drogas e seus efeitos sobre o cotidiano dos moradores, dirigia o seu foco a um segmento específico, a juventude. Não foi à toa que uma semana após a primeira reunião com a presidência da COHAB, uma audiência pública chamada pela Comissão de Transporte e Desenvolvimento Urbano da Assembleia Legislativa teve lugar na escola do bairro. Para minha surpresa, constatei uma significativa presença de moradores de várias localidades do bairro. Maior ainda foi a surpresa com a quantidade de participantes - moradores comuns, aqueles que não são nem pretendem ser lideranças, estavam lá, em uma noite chuvosa de inverno, acompanhando a audiência.

A luta pelo parque suscita reflexões sobre as demandas dos bairros da periferia. Os discursos em torno das crianças e dos jovens conquistavam maior apelo público entre os moradores. Vinham articulados à denúncia da discriminação sofrida por parte do poder público, e neles a condição de seu bairro e o tratamento recebido pelo poder público eram constantemente confrontados com a atenção dispensada à "Beira-Mar Norte" (essa avenida simboliza em seus discursos toda a riqueza da qual se encontram excluídos). Destacavam então o quanto isso afetava o cotidiano de seus jovens, que não tinham as mesmas oportunidades dos filhos dos moradores de outros bairros da cidade ${ }^{12}$. No contexto dessa construção discursiva, a contrapartida se traduzia na reivindicação por áreas de lazer no bairro. Juventude e infância em situação de risco, discriminação das periferias e ausência de investimento do Estado, tudo isso era incorporado ao idioma de ação daqueles que se mobilizavam no ou pelo bairro.

\footnotetext{
${ }_{12}$ Para a questão específica do parque, por exemplo, o urbanista e professor Lino Peres trazia dados argumentando em torno da necessidade de dez metros quadrados de área de lazer por habitante. A parte continental (bairro do Estreito) teria em torno de 0,5 metros quadrados por habitante. $O$ critério empregado pela Prefeitura Municipal de Florianópolis segue o defendido pelo Instituto Brasileiro de Administração de Municípios, que considera ideal cinco metros quadrados de área de lazer por habitante (PMF, 2009).
} 
Assim, no episódio do parque havia uma questão com potencialidade de mobilizar uma coletividade, tal como nas décadas passadas. E isso explica a forma como as lideranças colocaram-se em cena na luta pelo parque: motivadas, buscando articulações e mobilizações efetivas que garantissem o sucesso da reivindicação. O ímpeto com que se dedicaram a esta luta relaciona-se com a escassez de demandas com forte apelo de mobilização a serem encaminhadas pelas associações locais. Mostraram poder de decisão, conseguiram visibilidade, ocuparam o espaço político nessa questão (pequeno espaço, sem dúvida, se comparado com as conquistas do passado). Assim, avalio que não perderam a capacidade de mobilizar, nem se distanciaram de suas bases, mas perderam espaço. A cidade mudou e os espaços para o encaminhamento das demandas passaram a ser outros. Passou a exigir outro perfil de lideranças, tal como apontado por Edaléa Ribeiro (2005), que evidenciou em seu estudo com lideranças de movimentos sociais em Florianópolis a dificuldade do movimento de bairro em espaços que exigem outras habilidades (discurso bem articulado, tempo disponível à participação, o diálogo constante com autoridades). Um exemplo desse tipo de espaço foi o que envolveu todo um conjunto de atores na luta por um plano diretor participativo. Os representantes dos bairros mais pobres pouco participaram das plenárias destinadas à discussão e tomada de decisões relativas ao plano diretor. Nelas, o debate era pautado pelo conhecimento técnico de questões urbanísticas, pelo domínio da legislação, pela capacidade de agir e pensar estrategicamente os encaminhamentos políticos do plano diretor, e processos que envolviam negociações com o corpo de especialistas da prefeitura. As informações eram intensamente trocadas na internet, via listas de e-mails e grupos de discussão. Nesse contexto, as antigas lideranças dos bairros mais pobres, como é o caso do Monte Cristo, ficavam às margens do processo. Os protagonistas principais eram de bairros de camadas médias, muitos deles de nível universitário e, não raro, profissionais das áreas de urbanismo, direito e professores e estudantes universitários.

Alguns acontecimentos revelaram como essa perda de espaço foi sentida pelas lideranças do movimento. Numa reunião em que discutiam a escolha de nomes para compor a mesa de uma audiência pública na Assembleia Legislativa exclusivamente para discutir a questão do parque, rejeitaram de forma unânime a proposta de colocar à mesa 
o presidente de uma ONG, mesmo sendo ele ligado ao passado de lutas do bairro e com grande prestígio junto a seus moradores (pois ainda hoje desenvolve projetos voltados para crianças e jovens de áreas empobrecidas da cidade). Nas justificativas: "porque só para aparecer já tá cheio de gente". Em outros momentos, ouvi em reuniões do CARMOCRIS reclamações pelo fato de que os interlocutores das questões sociais passaram a ser as ONGs, e não mais os representantes das associações de moradores ou outras lideranças locais. "Tudo agora é resolvido com ele" (referindo-se ao diretor de uma ONG com forte trânsito entre empresários e políticos de todos os partidos), reclamava com forte ressentimento um antigo presidente de uma associação local.

O "aparecer" a que se refere a liderança também merece algumas considerações. Expressa a resistência a possíveis instrumentalizações do movimento, mas também espaço de disputa entre as lideranças. Instituições supralocais, como os partidos, ONGs e as universidades, são vistas como potenciais ameaças à autonomia das instituições locais. Não foi à toa que a luta pelo parque passou a dividi-los. Aqueles ligados ao partido Democratas (DEM) passaram a criticar a proposta pela qual cederiam apenas metade de toda a área para o parque. Os políticos dos diferentes partidos ligados às lideranças locais procuravam também ocupar o seu espaço quando das audiências. Embora o projeto do parque fosse de autoria de Lino Peres (ligado ao Partido do Trabalhadores- PT), a lei que o criou era de autoria de Ptolomeu Bittencourt, antigo vereador ligado ao DEM. O candidato desse partido, na época à prefeitura, César Souza Júnior, pronunciou-se também na defesa da proposta de que a área inteira do terreno da COHAB fosse cedida para o projeto original do parque.

A forma como a reivindicação do Parque Metropolitano conquistou apoio entre diferentes partidos corrobora com a compreensão que reivindica o caráter circunstancial e sujeito à natureza do jogo político presente na relação entre Estado e movimentos sociais. As audiências públicas, o modo como os políticos foram escolhendo suas posições, a forma como os órgãos estatais envolvidos no processo foram cedendo à reivindicação reforça o entendimento de que não há uma lógica pré-determinada (estabelecida, por exemplo, pela dinâmica da luta de classes), mas um jogo onde a ilusão do público assume contornos de realidade, por ser uma representação que se faz valer 
pela sua legitimidade, pelos valores que suscita e exige coerência de seus membros. César Souza Jr (assim como muitos políticos tidos pelos movimentos sociais como sendo conservadores) defende interesses populares, desde que esses não firam interesses de grupos que lhe dão apoio direto, ou questões exigidas pelo seu partido. Até porque seu eleitorado, diretamente vinculado à audiência do programa televisivo de seu pai (o comunicador César Souza), está diretamente vinculado aos moradores destas áreas periféricas da cidade. Mas, em coerência com o que coloca Claus Offe (1984), é possível afirmar que ele é "capitalista sem ser burguês"13: assume o jogo democrático, para além dos interesses imediatos da burguesia (ou de qualquer outro particular), representando os interesses de todos (ou da maioria), mas dentro dos limites da estrutura capitalista. E foi neste jogo político que os atores políticos do Monte Cristo obtiveram uma vitória.

\section{A cooperativa de artesanato}

Outro espaço organizativo criado na localidade foi o da cooperativa de artesanato: projeto de geração de renda, criado por iniciativa da universidade, cujo papel nem sempre foi entendido por todos. Sua história revela aspectos significativos acerca da dinâmica associativa na área. Observei o processo in loco, participando de suas reuniões, na qualidade de colaborador. Houve uma série de dificuldades de implementação pela pouca iniciativa dos cooperados. Esperavam para se reunir quando chegava o "pessoal da universidade". Quando havia iniciativa local, não raro desembocavam em conflitos que paralisavam as atividades até que chegassem os mediadores externos, guindados à posição de verdadeiros juízes de paz. Um dos grandes desafios na época era o de superar os conflitos internos, traduzidos na forma das fofocas ${ }^{14}$. Reclamavam do "diz-que-mediz", outras se referiam frequentemente ao fato de que se sentiam desestimulados à

\footnotetext{
${ }^{13}$ A esfera política incorpora o conjunto de interesses da sociedade, incluindo das classes dominadas, mas os interesses que se colocam dentro da esfera dos interesses capitalistas. Mesmo que tal reflexão tenha sido desenvolvida no contexto europeu do welfare state, acredito que tenha validade para se pensar a forma como no atual contexto classes sociais se articulam com uma esfera política que se pretende legitimar como democrática e plural.

${ }^{14}$ Analiso os relatos sobre a fofoca compartilhando da mesma compreensão da antropóloga Cláudia Fonseca em seus estudos com grupos populares urbanos em Porto Alegre: "A fofoca envolve, pois, o relato de fatos reais ou imaginados sobre o comportamento alheio. Ela é sempre concebida como uma força nefasta, destinada a fazer mal a determinados indivíduos. Ninguém se considera fofoqueiro, mas todo mundo concorda em dizer que há fofoca constantemente na vizinhança" (Fonseca, 2004: 41).
} 
participação porque tinha "muita falação na cooperativa". E a mediação dependeria sempre da presença dos universitários.

Todas as iniciativas em torno da associação de moradores e da cooperativa de artesanato evidenciavam o fato de que a dificuldade em articular espaços coletivos era constante. As pessoas optavam por evitar as disputas e conflitos inerentes a esses espaços recolhendo-se para suas vidas privadas. Prova disso era a forma que a fofoca ganhava centralidade, e tomava conta da cena local, servindo de argumento para que o espaço público fosse secundarizado ou mesmo abandonado. Embora a fofoca seja instrumental à definição dos limites do grupo, como bem observa Fonseca - pois ser objeto de fofoca representa integração ao grupo, fazer parte de um coletivo (2000, p. 42) - nesse caso, no modo como a crítica dos moradores à fofoca é colocada, ela tanto é tomada como sintoma de uma cena coletiva negativa como serve como justificativa para a retirada das pessoas desses espaços de sociabilidade, enfraquecendo mais ainda os laços coletivos.

A mediação dessas situações deveria ser feita por aqueles que estavam fora das relações de pertencimento afeitas à fofoca. Ou seja: dependiam de um mediador externo à "comunidade" - como colocado anteriormente, normalmente personificado na figura dos universitários. Como observou uma participante externa, era como se ficassem à espera de um patrão. Por mais críticos que fossem os universitários a essa situação de dependência, não encontraram mecanismos para reverter o quadro. No olhar dos universitários, o ideal comunitário frustrava-se, pois a perspectiva era da autonomia dos integrantes da cooperativa, e não da dependência: como se colocava na reunião, a ideia era "ensinar a pescar, e não dar o peixe". Vista sob esse ângulo, a cooperativa de artesanato apenas sobrevivia. As iniciativas autônomas eram insuficientes para a demanda de manter uma cooperativa de artesanato ativa.

O grande agravante era a deterioração da casa comunitária, que necessitava de uma reforma urgente para que pudesse abrigar equipamentos obtidos por um edital do MEC via universidade. Após conseguirem os recursos para a compra do material para a reforma de parte da casa comunitária, a situação foi resolvida com a obtenção de recursos para finalizar a reforma (pois o edital não previa mão de obra) via Secretaria 
Municipal do Continente. Com a ajuda de um professor com conhecimento de engenharia, houve quem então assumisse os encargos tanto de acompanhar a obra como de articular os encaminhamentos práticos da execução da obra com a secretaria. Com a casa concluída a aposta era de que poderia assim agregar mais pessoas, transcendendo o pequeno grupo (a "panela", como muitos vizinhos se referem ao grupo de mulheres envolvidas com a cooperativa) e a domesticação dos conflitos. Ao mesmo tempo, a conclusão da reforma da casa possibilitaria a criação de uma rotina, de uma organização do tempo e espaço, pré-condições para a realização de uma atividade profissional baseada no trabalho coletivo.

Mas havia dificuldade na relação com agentes externos. Existiam diferentes perspectivas entre universitários e demais agentes externos, de um lado, e as moradoras, de outro lado: enquanto os primeiros apostavam na autonomia, as mulheres buscavam reforçar os laços de dependência. Na perspectiva das mulheres cooperadas, o que os de fora colocavam como autonomia era percebido como abandono. A dependência era, na perspectiva delas, o apoio necessário para a realização de atividades para as quais não tinham conhecimento. Havia uma dificuldade, por exemplo, em organizar a secretaria e a contabilidade da associação. No entanto, o grupo contrapunha o fato de que havia entre as cooperadas uma técnica de contabilidade, e que faltava, portanto, iniciativa no sentido de querer tomar as iniciativas. No entanto, algumas dificuldades eram consensuais. Tal como a de realizar articulações externas, buscando espaços de vendas em feiras ou entre comerciantes (para colocar produtos em vendas consignadas) ou fazer acordos com fornecedores.

Mas se de um lado faltava esse capital social, de outro lado sobrava capital simbólico. Nas articulações com órgão estatais, na busca de apoios junto ao Terceiro Setor, o fato de estarem sob um projeto de geração de renda e sob a rubrica da inclusão social, e o fato de contarem com figuras que foram no passado emblemáticas dos movimentos sociais da cidade efetivamente abria muitas portas.

Acostumaram-se com muitos apoios: primeiro, na época da ocupação; depois, com as múltiplas atividades de projetos de extensão universitária. Posteriormente, houve um esvaziamento das atividades de extensão, permanecendo uma equipe menor de 
universitários atuando na localidade. Embora os principais agentes que atuavam nos projetos tenham se deslocado para outros trabalhos de inclusão social, de maior abrangência, mesmo que beneficiando os filhos dos moradores, tal fato foi visto por muitos como um abandono. O mesmo ocorreu quando da anunciada saída da coordenadora do projeto de geração de renda que dava apoio à cooperativa de artesanato: ainda que já prevista, também foi interpretada como "abandono".

Com este relato o que se pretende ressaltar é a dificuldade de organização coletiva em outros marcos que não aqueles que fizeram surgir a localidade, com base em mobilizações coletivas, formação de comissões de negociação, e organização de entidades representativas (associação de moradores ou comissão de moradores). É importante estabelecer o contraste com o episódio da luta pelo Parque Metropolitano, no qual a ação coletiva no parâmetro historicamente consolidado, com base na associação de moradores e em uma entidade articuladora das associações, obteve êxito, com os atores conseguindo atingir seus objetivos políticos.

\section{Considerações finais}

O contexto atual de localidades como a analisada neste artigo, historicamente abandonadas ou relegadas a um segundo plano no atendimento de suas necessidades pelo Estado, é de ampliação de ações compensatórias, provenientes tanto do Estado como de entidades do Terceiro Setor, voltadas a essas populações (ou "comunidades", outro eufemismo largamente empregado). Mas tais ações vêm concorrendo com o papel que outras instituições estatais historicamente desempenharam, tal como é o caso da escola. Como disse um dos jovens entrevistados: "a escola ensina a ler e escrever; o resto é a vida que ensina". Outras instituições passaram a se encarregar dos ensinamentos imputados à escola, como aqueles saberes relacionados à profissionalização, os quais, no caso dos atores aqui investigados, nunca chegaram a se realizar (se considerarmos o histórico de escolarização e formação para o trabalho das gerações anteriores). Assim, na medida em que predomina o baixo investimento público, refletindo-se diretamente na qualidade de ensino (os resultados do IDEB comprovam), a escola perde terreno. $O$ 
mesmo baixo investimento ocorre também com relação aos postos de saúde. Acresce a isto o estigma: tem sido comum ouvir relatos de professores e profissionais da saúde que preferem evitar trabalhar nesses bairros.

Daí a preocupação na superação de estigma, contrapondo ao emprego do termo favela a defesa enfática da comunidade. Na medida em que projetos de natureza socioeducativa trabalham no sentido de elevação de autoestima, de valorização da cultura local, obtêm respaldo entre os moradores.

O que surpreende é que ainda assim as lideranças buscam (e encontram) espaços de interlocução com estas instituições. Com todas as dificuldades, esta esfera intermediária, designada como paroquial, incorpora uma dinâmica própria, mesmo que prejudicada em sua autonomia, lidando com relações clientelistas e precisando se adaptar a novas formas de articulação de suas demandas. Neste particular, as ONGs e os projetos parecem se constituir como as novas referências, se tomarmos como parâmetro as formas como se engendravam as ações coletivas que fizeram surgir muitas das localidades do bairro.

Mesmo com as dificuldades, não é possível falar em laços fracos. Há uma forte relação de pertencimento, que pode ser reportada a uma memória que positiva o passado. A área se produziu de um modo diferenciado, e isto faz diferença, inclusive no sentido de provocar o estranhamento daqueles que conhecem o histórico de lutas, e o surgimento da localidade e do bairro. Isso pode relativizar o esvaziamento. As mudanças aconteceram: as formas de articulação coletiva, que no passado haviam consolidado novos atores políticos na cidade, foram acompanhadas de mudanças nas sociabilidades no plano local, em um processo no qual cada vez mais passaram a predominar estratégias individualizadas de inserção de seus moradores na cidade. No caso aqui analisado impressiona o contraste entre um presente de "privatização das relações" e um passado pleno de "articulações coletivas e projetos de transformação".

No entanto, o episódio da luta pelo Parque evidencia que as lideranças têm ainda capacidade de mobilizar os moradores e, mais do que isso ( uma vez que a participação coletiva, envolvendo grande número de moradores, está cada vez mais difícil), de enfrentar seus opositores na esfera ampliada da cidade. Para isso, valem-se de 
assessorias e lançam mão de eficazes estratégias de negociação. É possível argumentar que tal conquista (a do Parque) seja de natureza episódica, que apresenta capacidade de pressão e articulação no plano paroquial, mas que seria inerente a este tipo de ação coletiva conviver com uma dificuldade de atingir a e de se legitimarem na esfera citadina. Mas este talvez seja o principal desafio de se pensar uma política de fato democrática na cidade.

\section{Referências Bibliográficas}

BAUMAN, Zygmunt. Comunidade: a busca por segurança no mundo atual. Rio de Janeiro: Zahar, 2003.

CANELLA, Francisco. Entre o local e a cidade: memórias e experiências de duas gerações de moradores da periferia urbana em Florianópolis. 2011, Tese (Doutorado) - Universidade do Estado do Rio de Janeiro. Instituto de Filosofia e Ciências Humanas.

CANELLA, Francisco; VIDAL, Leandro; PITTA, André. Relatório Final de Pesquisa: A escola e a cidade. Florianópolis, UDESC, 2004.

FONSECA, Claudia. Família, fofoca e honra: etnografia de relações de gênero e violência em grupos populares. Porto Alegre, Editora da UFRGS, 2004.

FREITAS, Guaciara Barbosa. A cultura na (da) periferia e a periferia na (da) mídia. Políticas culturais em revista, v.2, n.2, p. 34-49, 2009.

HUNTER, Albert. Private, parochial and public social orders: the problem of crime and incivility in urban communities. In: SUTTLES,G; ZALD, M. (Ed.). The challenge of social control. Norwood (NJ) : Ablex Publishers, 1985.

NOVAES, Regina. Os jovens de hoje: contextos, diferenças e trajetórias. In: ALMEIDA, Maria Isabel Mendes e EUGÊNIO, Fernanda. (Org.). Culturas jovens: novos mapas do afeto. Rio de Janeiro : Jorge Zahar Ed., 2006

OFFE, Claus. A Democracia Partidária Competitiva e o welfare state keynesiano: fatores de estabilidade e desorganização". IN: Problemas estruturais do estado capitalista. Rio de Janeiro : Biblioteca Tempo Brasileiro, 1984 
RIBEIRO, Edaléa Maria. Movimentos Sociais em tempos de democracia e globalização em Santa Catarina: os anos 90. Florianópolis: Fundação Boiteaux, 2005.

SARLO, Beatriz. Tempo passado: cultura da memória e guinada subjetiva. São Paulo: Companhia das Letras; Belo Horizonte: UFMG, 2007.

SIMMEL, Georg. Questões fundamentais da sociologia: indivíduo e sociedade. Rio de Janeiro : Jorge Zahar, 2006.

SIMMEL, Georg. A metrópole e a vida mental. In: VELHO, Otávio (Org.). O fenômeno urbano. Rio de Janeiro: Zahar, 1979.

WACQUANT, L. Os condenados da cidade. Rio de Janeiro: Revan, FASE, 2005.

WHYTE, William Foote. Sociedade de esquina: a estrutura social de uma área urbana pobre e degradada. Rio de Janeiro: Zahar, 2005.

ZAGO, Nadir. Processos de escolarização nos meios populares - as contradições da obrigatoriedade escolar. In: NOGUEIRA, Maria A, ROMANELLI, Geraldo, ZAGO, Nadir (Org.). Família e escola: trajetórias de escolarização em camadas médias e populares. Petrópolis (RJ) : Vozes, 2001.

ZALUAR, Alba. Gangues, galeras e Quadrilhas: globalização, juventude e violência. In: VIANNA, Hermano (org.) Galeras cariocas: territórios de conflitos e encontros culturais. Rio de Janeiro : Editora da UFRJ, 2003.

ZALUAR, Alba; RIBEIRO, Ana Paula Alves. Teoria da eficácia coletiva e violência: o paradoxo do subúrbio carioca. Novos Estudos, n. 84, julho de 2009. 
Recebido em: 27/05/2013 Aprovado em: 14/10/2013

Universidade do Estado de Santa Catarina - UDESC Centro de Ciências Humanas e da Educação - FAED

Revista PerCursos

Volume 14 - Número 27 - Ano 2013 revistapercursos@gmail.com 